\title{
A TRAJETÓRIA DA ESCOLA DE APLICAÇÃO DE LARANJEIRAS DO SUL -PR: 1968 a 1980 - ASPECTOS HISTÓRICOS
}

Lucimara Lemiechek ${ }^{1}$

\begin{abstract}
Resumo: este artigo apresenta aspectos históricos da Escola de Aplicação do município de Laranjeiras do Sul- PR no período compreendido entre os anos de 1968 a 1980. Frente a necessidade da existência de um campo de práticas para alunos da Escola Normal Secundária, a falta de vagas para o ensino primário na única escola pública da zona urbana e a possibilidade de inserção no mercado de trabalho de normalistas recém-formados, a escola foi criada em 24 de fevereiro de 1968. O objetivo era resolver esses impasses e, ao mesmo tempo, elevar a qualidade de ensino na região por meio da atuação de profissionais habilitados. Ao final de 25 anos de atividades da instituição analisaremos os motivos de sua criação, sua trajetória e os reais objetivos alcançados por ela.

Palavras-chave: História da Educação, Laranjeiras do Sul, Escola de Aplicação, formação de professores, escola primária.
\end{abstract}

\section{THE TRAJECTORY OF LARANJEIRAS DO SUL'S ESCOLA DE APLICAÇÃO: FROM 1968 TO 1980 - HISTORICAL ASPECTS}

\begin{abstract}
This article presents historical aspects of the Laranjeiras do Sul's Escola de Aplicação, municipality of Paraná State, from 1968 to 1980. Facing the need for a field of practices for students of the Normal Secondary School, a lack of vacancies for the elementary school in the only urban public school, and the possibility of insertion of these newly graduated students into the job market, the school was founded on February 24, 1968. The goal was to solve the standoffs mentioned, as well as make teaching quality higher in the region through the performance of skilled professionals. After 25 years of operation of this institution, we seek to analyze the reasons for its creation, its path and the real goals achieved by it.
\end{abstract}

Keywords: History of education, Laranjeiras do Sul, Escola de Aplicação, teachers' formation, primary school.

\section{Introdução}

As primeiras escolas de Aplicação foram criadas no século XIX em São Paulo, dentro das reformas implantadas naquele estado que foi o pioneiro na reorganização do ensino no Brasil (LEMIECHEK, 2014). Mais tarde, a finalidade dessas instituições foi prevista na Lei Orgânica do Ensino Normal que determinava que: “Art. 47. Todos os estabelecimentos de ensino normal manterão escolas primárias anexas para demonstração e prática de ensino" (BRASIL, 1946).

Neste trabalho investigamos aspectos da Escola de Aplicação do município de Laranjeiras do Sul - PR criada para a realização das práticas dos alunos da Escola Normal Colegial Leôncio Correia, inserção dos normalistas recém-formados no mercado de trabalho e ampliação do número de vagas para o ensino primário na zona urbana. O texto está assim estruturado: inicialmente abordaremos o surgimento das escolas de aplicação no Brasil e, em seguida, contextualizaremos a criação da instituição em Laranjeiras do Sul no ano de 1968. Dando sequência, analisaremos a estrutura física, corpo docente e discente e aspectos

\footnotetext{
${ }^{1}$ Licenciada em Pedagogia pela Universidade Estadual do Centro-Oeste (UNICENTRO) e mestre em Educação pela Universidade Estadual do Oeste do Paraná (UNIOESTE) campus Francisco Beltrão. Pedagoga na Universidade Federal da Fronteira Sul campus Laranjeiras do Sul-PR. luspassin@uffs.edu.br
} 
pedagógicos. A metodologia utilizada é revisão bibliográfica fundamentada em nossa dissertação de mestrado defendida no ano de 2014 intitulada "Aspectos históricos da formação de professores normalistas no município de Laranjeiras do Sul - PR (1946 - 1980)" e nos trabalhos de estudiosos da historiografia da educação como Hervatini (2011), Miguel (1997) e Tanuri (2000).

\section{As escolas de aplicação no Brasil}

De acordo com Tanuri, a criação de escolas destinadas a preparar professores para o exercício de suas funções está atrelada "à institucionalização da instrução pública no mundo moderno, ou seja, à implementação das ideias liberais de secularização e extensão do ensino primário a todas as camadas da população" (2000, p.14). No Brasil, as escolas de formação de professores, ou escolas normais, demoraram a se constituir efetivamente como lócus de aprendizado para o desempenho da função de docente. A primeira escola normal foi criada na província do Rio de Janeiro em 1835 e a instabilidade pairou, por muitas décadas, sobre as instituições precursoras desta modalidade.

Com o advento da República os estados se tornaram responsáveis pela educação elementar e passaram a organizar os seus sistemas. Estados progressistas saíram à frente nas reformas e São Paulo se apresentou como modelo para os demais devido à inovação estrutural e pedagógica que propunha ao ensino elementar. De acordo com Tanuri, a reforma paulista iniciada em 1890 alterou o currículo da escola normal e "contemplou as suas escolas-modelo anexas, bem como a prática de ensino que os alunos deveriam ali realizar" (2000, p. 69). Estava lançada a semente do que, mais tarde, chamaríamos de Escolas de Aplicação.

No Paraná as mudanças iniciaram em 1920 com o reformador Prieto Martinez e, entre outras medidas por ele adotadas, destaca-se a criação de grupo escolar anexo à Escola Normal “para a realização da prática pedagógica segundo os modelos paulistas" (MIGUEL, 1997, p.33).

Desta forma, e com a ênfase no termo "escola-modelo", essas instituições passaram a se constituir lócus essencial para o desenvolvimento das práticas pedagógicas apreendidas. Mais tarde, com a promulgação da Lei Orgânica do Ensino Normal em 1946, determinou-se que toda Escola Normal mantivesse uma escola primária anexa para as práticas pedagógicas.

\section{O contexto de criação da Escola de Aplicação}

Para compreender aspectos da Escola de Aplicação de Laranjeiras do Sul- PR, precisamos retroceder no tempo. A história da formação de professores no município iniciou-se em 1946 com a criação do Curso Normal Regional quando esta chamava-se Iguaçu e era a 
capital do Território Federal do Iguaçu. O Curso Normal Regional, formava regentes primários, ou seja, professores para trabalhar nas escolas isoladas ${ }^{2}$ e equivalia a um nível superior ao primário, no caso o ginasial, com quatro séries. A partir de meados da década de 1950 uma outra escola de formação de professores, desta vez em nível colegial, se fazia necessária no município iniciando-se as discussões e movimentação da população, de profissionais do meio educacional e representantes do Poder Público para que ela fosse criada. Segundo Lemiechek "na época do início das discussões acerca de sua criação, o município apresentava o seguinte quadro educacional: 3 Grupos Escolares (apenas um na sede com 545 alunos), 28 casas escolares (906 alunos), 1 Escola Normal Regional (80 alunos), 1 Ginásio (30 alunos), 2 escolas particulares (número incerto de alunos) e 41 escolas municipais (1.717 alunos)” (2014, p. 141). Convém salientar que, dos Grupos Escolares, apenas o Grupo Escolar Tiradentes era localizado na sede e os demais ficavam em distritos longes do centro urbano. Assim, eram dois os problemas educacionais que precisavam ser solucionados: havia apenas uma escola primária pública na zona urbana e não havia estabelecimento que ofertasse o $2^{\circ}$ ciclo do ensino médio para atender os jovens que se formavam em nível ginasial. Havia, portanto, uma lacuna educacional de uma década em que os concluintes do nível ginasial ficaram sem estudar ou tiveram que se deslocar para outros municípios. Além disso, era necessário formar professores num grau mais elevado de ensino. Para Miguel

O plano dos cursos normais regionais era preparar o futuro professor, considerando que ele não havia cursado o ginásio, mas que conforme previa a Lei Orgânica do Ensino Normal, poderia após concluir o normal regional, vir a cursar o normal colegial. Deste modo, pensava Pilotto que a política a ser seguida seria de, após formadas as primeiras turmas dos normais regionais, nas mesmas localidades e conservando tais cursos, abrir escolas normais colegiais e, ao mesmo tempo, difundir o ensino secundário (ginásio) (1997, p. 149).

Desta forma, a Escola Normal Secundária de Laranjeiras do Sul foi criada pelo Decreto n 11.292 assinado pelo ex-governador do Estado do Paraná Moysés Lupion em 11 de julho de 1957. Depois passou a denominar-se Escola Normal Secundária Dr. Leôncio Correia e mais tarde Escola Normal Colegial Estadual Dr. Leôncio Correia até o final de sua existência. De acordo com Lemiechek, mesmo que tardiamente, considerando que o Curso Normal Colegial funcionava desde 1958, “[...] para melhor cumprir com o objetivo da formação de professores para $1^{\mathrm{a}}$ a $4^{\mathrm{a}}$ séries, deu-se a criação da Escola de Aplicação, onde os alunos desenvolviam seu estágio de observação, participação e regência de classe" (2014, p. 144). Assim, em 24 de

\footnotetext{
${ }^{2}$ Escolas que tinham apenas uma turma e um professor, funcionando de forma multisseriada e majoritariamente na zona rural (BRASIL, Decreto-Lei no 8.530, 1946).
} 
fevereiro de 1968, o governador Paulo Pimentel assinou o Decreto ${ }^{\circ} 9.090$ criando a Escola de Aplicação de Laranjeiras do Sul, anexa à Escola Normal Dr. Leôncio Correia.

Além desse requisito legal, outros motivos impulsionaram a criação da escola. Segundo depoimentos orais de entrevistados, artigos de jornais da época e históricos encontrados nas escolas pesquisadas, o Grupo Escolar Aluísio Maier, o único a oferecer ensino primário público na zona urbana estava superlotado, oferecendo aulas em três turnos com a ocupação do salão e outras dependências destinadas ao administrativo para acomodar o grande número de turmas. Embora houvesse no município o Colégio Vicentino Santa Ana e a Escola Adventista, estas eram instituições particulares destinadas, portanto, às famílias que podiam pagar pelos estudos de seus filhos. Houve então a demanda da população laranjeirense por uma nova escola pública que atendesse os alunos da sede do município.

A professora Anastácia Leonora Brum, que fez parte do primeiro quadro docente formado para trabalhar na instituição, durante entrevista, apontou outro motivo para a abertura da Escola de Aplicação: a dificuldade que alguns normalistas tinham, especialmente as mulheres, de trabalhar nas escolas isoladas do interior:

[...] Eu sempre penso que eles tinham que dar mais condição pra quem trabalhava, e todo mundo sabe que pra ir pra fora, uma professora dona de família, ela não tinha condição. Então vários problemas que surgiam na época que daí eles se obrigaram a criar uma escola pra dar oportunidade pra mulherada, porque na maior parte era só mulher mesmo (BRUM, 2014).

Em seu depoimento, a professora Anastácia citou a criação da Escola de Aplicação como uma forma de inserir no mercado de trabalho as normalistas que não se interessavam ou que, por algum motivo, não podiam lecionar no interior do município. Conforme Hervatini, a oferta do ensino seriado dos grupos escolares e, nesse caso, da Escola de Aplicação “[...] possibilitou o atendimento a um maior número de alunos, necessitando de mais professores, cada um responsável por uma turma, pertencente a uma mesma série” (2011, p. 104). Dessa forma, oportunizava-se mais vagas para professores que queriam lecionar, mas que, por motivos diversos, não podiam se deslocar para fora da sede do município.

\section{Histórico da estrutura física}

De acordo com Lemiechek (2014), a exemplo da maioria das instituições de ensino do país, a escola de Aplicação também enfrentou muitos problemas com relação à sua estrutura física. No início das atividades, e até o ano de 1972, funcionou anexa à Escola Normal Colegial Estadual Dr. Leôncio que se localizava em local privilegiado: no centro da cidade, ao lado da 
Igreja Matriz Santana. Como dividia espaço com a Escola Normal, nessa época, as aulas da Escola de Aplicação eram apenas no período vespertino.

Instalações da Escola Normal Colegial Estadual Dr. Leôncio Correia

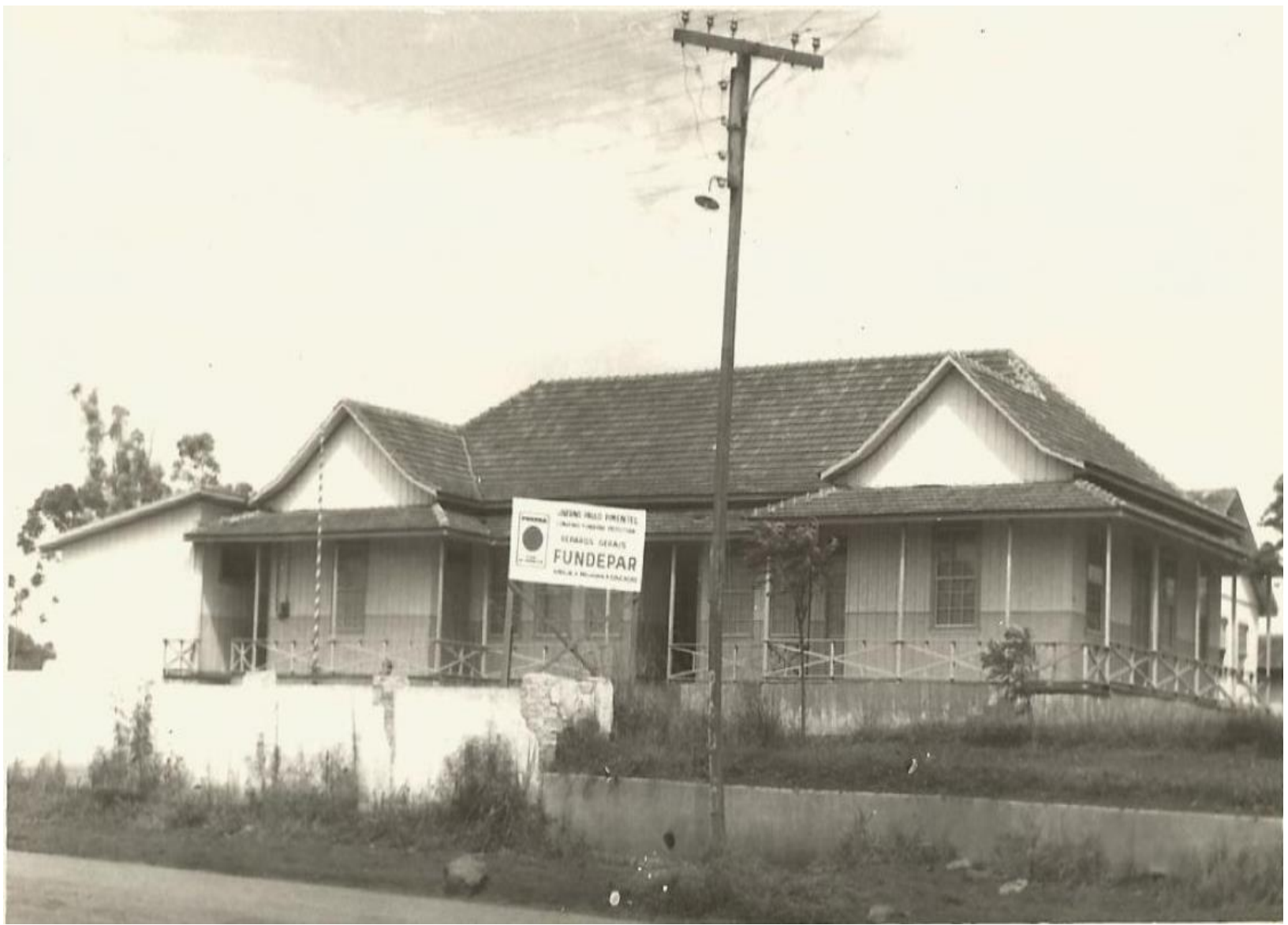

Fonte: acervo da família Camargo

No entanto, no final do ano letivo de 1972 devido à problemas na estrutura do prédio, condenado por estar em situação precária em decorrência da falta de manutenção, as duas escolas foram transferidas. A Escola de Aplicação passou a funcionar em um prédio particular cedido pela Associação das Damas de Caridade. Neste local havia funcionado o Hospital de Caridade e ficava situado à Rua Manoel Ribas, $n^{\circ}$ 280. Era uma construção de tamanho considerável, no entanto, o local não oferecia as condições ideais para as atividades de ensino. As salas eram pequenas e com pouca ventilação, havia uma varanda alta e perigosa para os alunos na parte dos fundos, não possuía instalações sanitárias no interior do prédio, entre outras dificuldades. Mesmo assim, de forma improvisada, ela permaneceu naquele espaço entre os anos de 1973 a 1977 até a construção de novo prédio no final da década. 
O antigo Hospital de Caridade

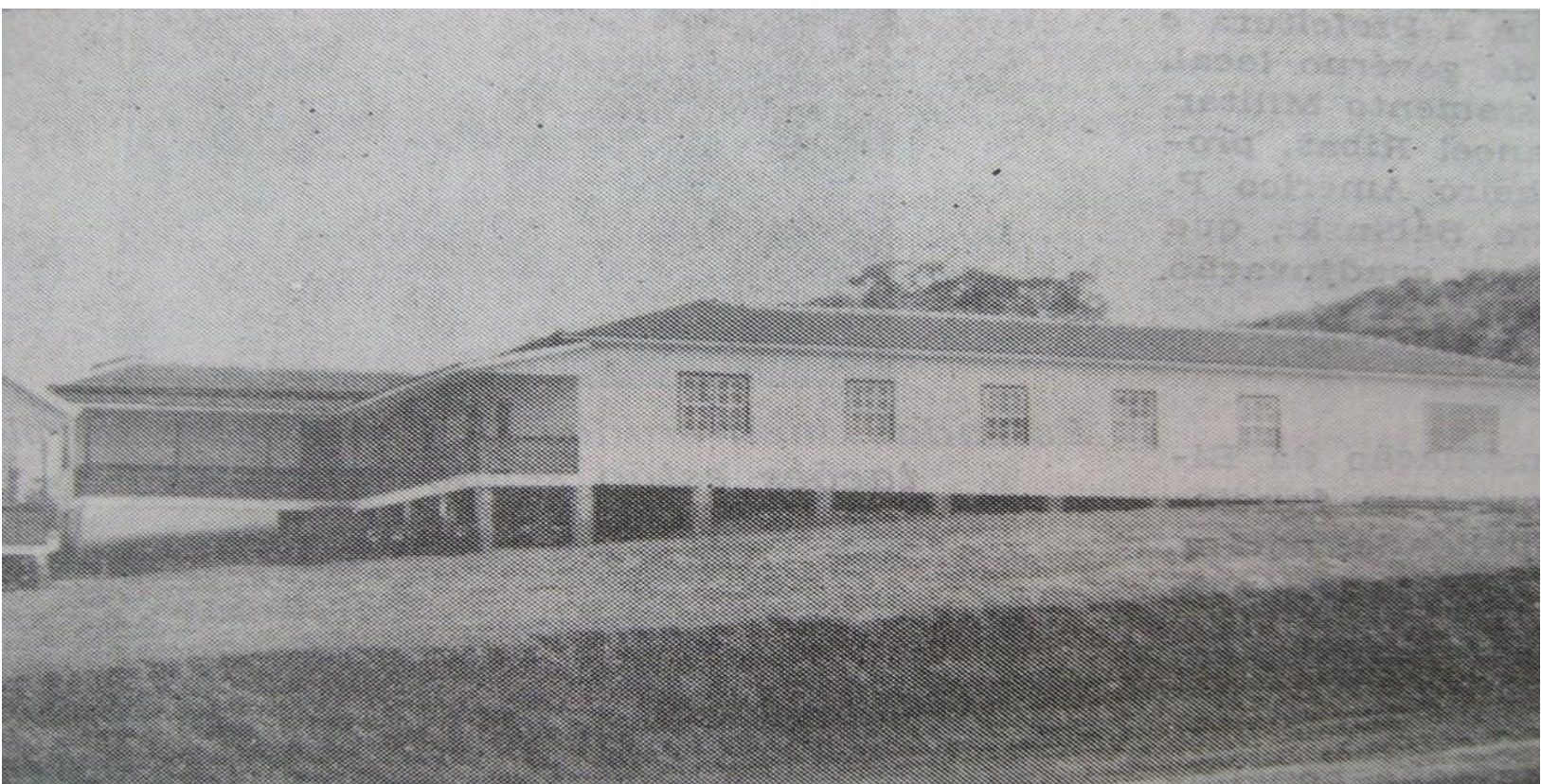

Fonte: Revista Tribuna Laranjeirense. 1971, p. 8.

No mesmo ano em que a escola foi transferida para o antigo hospital (1973), a Prefeitura Municipal na gestão do prefeito Rangel de Souza Muller doou um terreno para a construção do prédio que abrigaria as escolas Normal Colegial Estadual Dr. Leôncio Correira e de Aplicação. Porém, sua construção, além de não ter sido realizada conforme a especificação do projeto original, foi morosa e a obra foi inaugurada apenas no início do ano de 1978 possuindo somente 6 salas de aula.

Construção das novas instalações da Escola de Aplicação

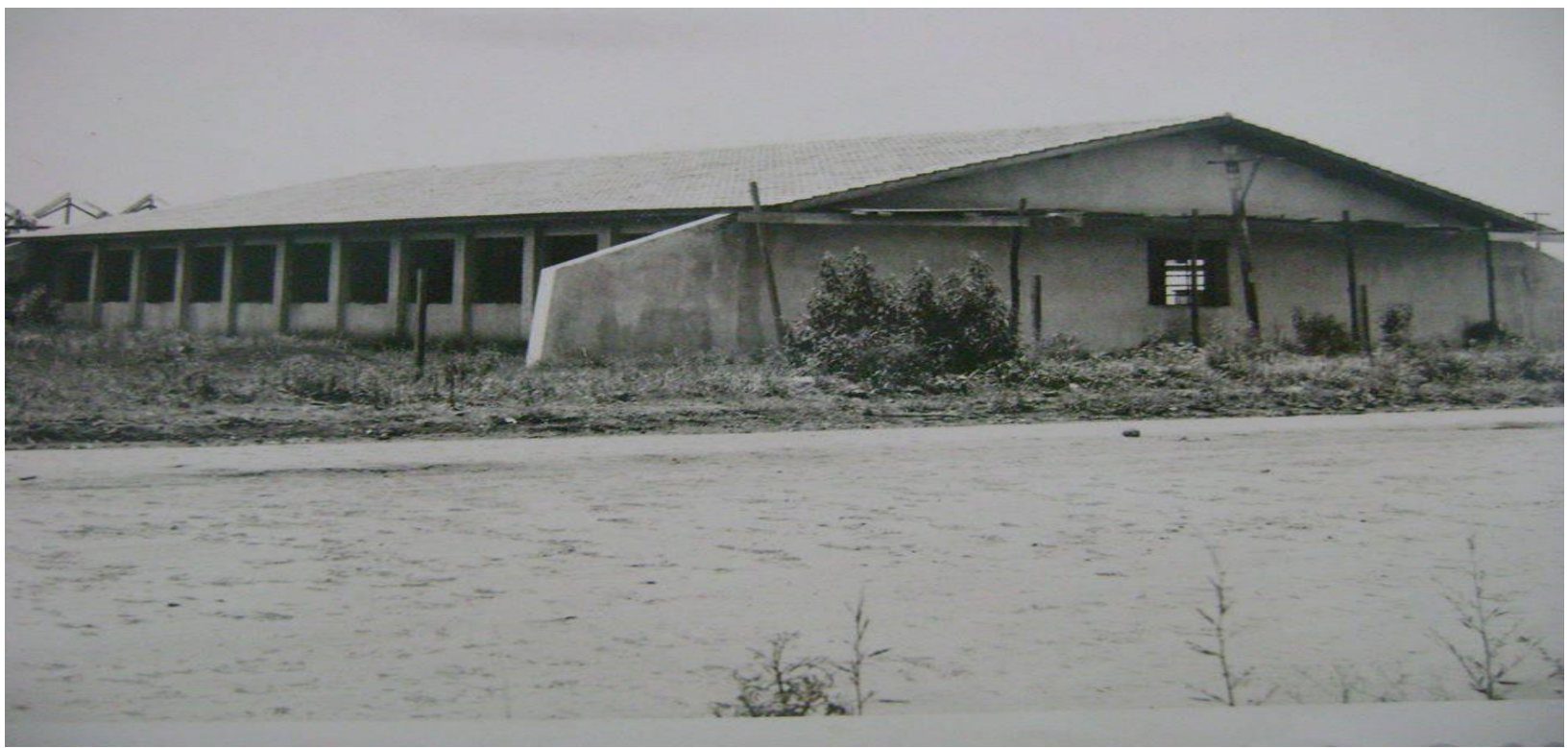

Fonte: Biblioteca Pública Municipal Elizeu Anacleto Babinski. 
Após a mudança, o espaço foi dividido com mais uma instituição: a Escola de Comércio Otaviano Amaral que depois de reorganização e fusão com a Escola Normal Colegial Estadual Dr. Leôncio Correia passou a denominar-se Colégio Estadual Honório Babinski - Ensino de $2^{\circ}$ Grau ofertando as habilitações plenas de Magistério (diurno), Contabilidade (noturno) e Básica em Agropecuária (diurno) com a implantação gradativa das primeiras séries a partir de 1979. Em 1980, o governador Ney Braga autorizou o funcionamento do Complexo Escolar Dom Manoel Koenner - Ensino de $1^{\circ}$ e $2^{\circ}$ Graus. Houve a reorganização da Escola de Aplicação e Colégio Estadual Honório Babinski que passaram a se constituir um único estabelecimento de ensino com a denominação de Colégio Professor Gildo Aluísio Schuck - Ensino de $1^{\circ}$ e $2^{\circ}$ Graus. Na década seguinte, devido à municipalização, o $1^{\circ}$ Grau do Colégio Estadual Professor Gildo Aluísio Schuck - Ensino de $1^{\circ}$ e $2^{\circ}$ Graus, ou seja, a Escola de Aplicação, passou a denominarse Escola Municipal Padre Gerson Galvino funcionando anexa a esse estabelecimento de Ensino, porém sob dependência administrativa da Secretária de Educação do município e não mais do Governo do Estado do Paraná. Hoje a Escola Municipal Padre Gerson Galvino se encontra em prédio próprio construído pelo município. Assim, entre a criação da Escola de Aplicação (1968) e a sua municipalização (1993) passaram-se vinte e cinco anos.

\section{Corpo docente e discentes}

Antes de falarmos sobre professores e alunos, convém um esclarecimento: desde sua criação até a municipalização no ano de 1980, verificamos que o quadro docente da Escola de Aplicação foi essencialmente feminino conforme era comum na época num fenômeno de feminização do magistério que acontecia em todo o Brasil. Não localizamos nos documentos e nem nos depoimentos orais o nome de professor que houvesse trabalhado na escola. Desta forma, utilizaremos os termos sempre no feminino ao nos reportarmos ao corpo docente.

As aulas na Escola de Aplicação se iniciaram em fevereiro de 1968 logo após a criação da instituição tendo como primeira diretora a professora Terezinha Mathilde Zempulski e como secretária a professora Esther Araújo Cordeiro. Nesse início de atividades ainda não havia a figura da coordenação pedagógica, ficando a escola sob a responsabilidade da direção e secretaria tanto os aspectos pedagógicos como administrativos. 


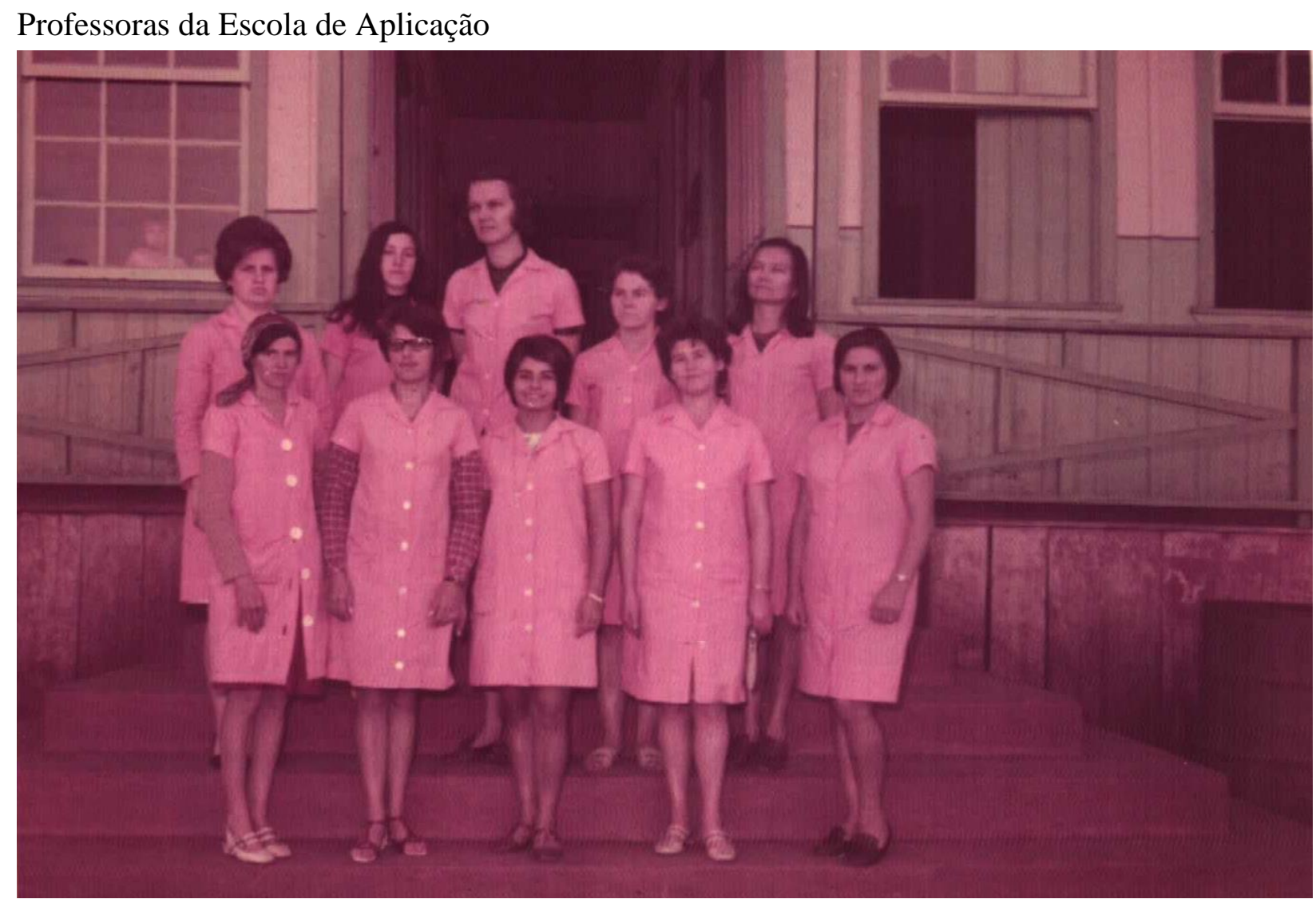

Fonte: acervo pessoal de Anastácia Leonora Brum

$\mathrm{Na}$ fotografia acima temos um dos primeiros quadros docentes da escola. Apesar de estar sem data, devido ao local inferimos que ela foi tirada entre os anos de 1968 a 1972. Embaixo, da esquerda pra direita: Geni F. do Nascimento, Laura Folda Mezzomo, Iria da Silva Motta, Esther Araújo Cordeiro e Olga Musyka. Acima, também da esquerda para a direita as professoras: Iwelda Kossatz Mattos, Jurema Marques Fritz, Terezinha Mathilde Zempulski, Amélia Josefi e Anastácia Leonora Brum. No início, trabalhavam na escola apenas professoras do Estado, no entanto, com o passar do tempo a estas se juntaram professoras municipais. Com a municipalização em 1993, restaram poucas professoras do Estado que permaneceram vinculadas à escola até a aposentadoria.

Nem todas as docentes ingressaram na Escola de Aplicação da mesma forma. Embora já houvesse concurso público do Estado, no início das atividades da instituição ainda funcionavam os contratos anuais e havia ingerência política para a escolha das professoras que seriam contratadas. Portanto, havia a contratação de professoras leigas em detrimento às egressas das Escolas Normais. Vejamos os casos específicos de duas professoras que trabalharam na Escola de Aplicação: 
$[\ldots]$ naquela época nomeação não era como hoje que você tem que se preparar porque você vai enfrentar um testão, uma coisa assim. Aquele tempo não. Era política. Então poderia ter sido nomeada, se fosse que nem fazer testes, coisa assim, uns três anos antes. Mas, como era problema político então quem não rezava de acordo com o que era da época...Foi me dito na cara: "Anastácia, você não teve sorte dessa vez". E daí, uma vez eu fui pedir que fizessem o favor de pensar em mim porque eu não tinha pai mais, porque eu perdi meu pai tinha só dez anos. [...] mas o problema era demais porque numa das vezes que a gente soube que tinham trazido nomeações, só para uma casa três foram sorteadas e a gente não tinha ainda oportunidade" (BRUM, 2014).

A professora Maria Izabel Marcinko confirma as palavras de Anastácia quanto à interferência política e explica a forma como ingressou no magistério: "Sim. Eu sou concursada. Eu sou do segundo concurso do Estado. [...] antes não tinha. Era só nomeado, apadrinhado. Achava os padrinhos lá...no nosso tempo já não era mais. Já era através de concurso" (MARCINKO, 2014).

Depois de assumir a vaga em concurso e lecionar por dois anos no Grupo Escolar Eurico Gaspar Dutra em Virmond, ela conta como foi sua transferência para a Escola de Aplicação, na qual permaneceu até se aposentar no início da década de 1990:

[...] eu fui convidada porque faltou professora aqui, sabe? Eu era bastante amiga e também fui aluna da Tereza, da Anastácia e tudo, e elas que trabalhavam lá e solicitaram ali no Núcleo e daí me chamaram para passar pra cá. Mas para mim foi surpresa que eu não sabia. Eu fiquei louca de faceira, imagina! Trabalhar aqui na cidade, não precisava me deslocar. E daí trabalhei até me aposentar na mesma escola (MARCINKO, 2014).

Ao cruzarmos dados durante a pesquisa observamos, por exemplo, que determinada professora assumiu uma $1^{\mathrm{a}}$ série da Escola de Aplicação no ano de 1968 quando estava na $1^{\mathrm{a}}$ série da Escola Normal Secundária onde se formaria apenas no ano de 1970, sendo portanto, uma professora inabilitada para trabalhar naquela escola. Na época, ela possuía apenas o Normal Ginasial que a habilitava ao trabalho em escolas isoladas. Esse fato ia, portanto, de encontro a legislação estadual promulgada em 1964 quando foi criado o Sistema Estadual de Educação. A única explicação plausível, considerando que na época já existiam muitas professoras formadas no Curso Normal Colegial, é a interferência política conforme relatado pelas professoras Maria Izabel e Anastácia, embora ambas não houvessem citado nomes, apenas situações.

Ainda de acordo com as pesquisas de Lemiechek (2014), a escola foi conduzida pela professora Therezinha Mathilde Zempulski entre os anos de 1968 até 1975 quando, por meio do ofício $n^{\circ} 83 / 75$ datado de 24 de novembro, o Inspetor Felix Szeszerbicki da $46^{\text {a }}$ Inspetoria Regional de Ensino determinou que a professora Esther Araújo Cordeiro assumisse a direção em decorrência da solicitação de afastamento por parte da diretora anterior. A professora Esther 
ficou temporariamente no cargo até a indicação da professora Olga Pereira Muzyka que respondeu pela direção a partir de 1976 até meados da década de 1980 sendo, desta forma, direções continuadas e longevas.

O quadro abaixo apresenta o número de turmas e alunos matriculados na escola entre os anos de 1968 a 1980, bem como o nome das professoras. Optamos pela delimitação deste período em virtude de serem, respectivamente, os anos de criação da escola e da desativação da Escola Normal Colegial Estadual Dr. Leôncio Correia a qual ela estava vinculada. Os dados foram coletados por meio do livro de registro de matrículas e das atas de exames finais da Escola de Aplicação nos quais eram registrados os resultados finais do rendimento escolar anual de todos os alunos.

Número de turmas, alunos e respectivas docentes da Escola de Aplicação entre os anos de 1968 a 1980.

\begin{tabular}{|c|c|c|c|c|}
\hline Ano & Professor & Série & $\begin{array}{l}\text { Número } \\
\text { de alunos }\end{array}$ & Total \\
\hline 1968 & $\begin{array}{l}\text { Laura Folda Mezzomo } \\
\text { Olga Pereira Muzyka } \\
\text { Jurema Marques Fritz } \\
\text { Ione Barbosa Levandoski }\end{array}$ & $\begin{array}{l}4^{\mathrm{a}} \\
3^{\mathrm{a}} \\
2^{\mathrm{a}} \\
1^{\mathrm{a}}\end{array}$ & $\begin{array}{l}22 \\
25 \\
35 \\
43\end{array}$ & 125 \\
\hline 1969 & $\begin{array}{c}\text { Amélia Josefi } \\
\text { Iwelda Kossatz Mattos } \\
\text { Geni F. do Nascimento } \\
\text { Olga Pereira Muzyka } \\
\text { Iria da Silva Motta } \\
\text { Albertina Alberti Piasecki }\end{array}$ & $\begin{array}{l}4^{\mathrm{a}} \\
3^{\mathrm{a}} \\
2^{\mathrm{a}} \\
2^{\mathrm{a}} \\
1^{\mathrm{a}} \\
1^{\mathrm{a}}\end{array}$ & $\begin{array}{l}19 \\
29 \\
15 \\
21 \\
23 \\
27\end{array}$ & 134 \\
\hline 1970 & $\begin{array}{l}\text { Laura Folda Mezzomo } \\
\text { Amélia Josefi } \\
\text { Jurema Marques Fritz } \\
\text { Albertina Alberti Piasecki } \\
\text { Iraci Franciosi }\end{array}$ & $\begin{array}{l}4^{\mathrm{a}} \\
3^{\mathrm{a}} \\
3^{\mathrm{a}} \\
2^{\mathrm{a}} \\
1^{\mathrm{a}}\end{array}$ & $\begin{array}{l}26 \\
25 \\
26 \\
24 \\
25\end{array}$ & 126 \\
\hline 1971 & $\begin{array}{c}\text { Albertina Alberti Piasecki } \\
\text { Olga Pereira Muzyka } \\
\text { Amélia Josefi } \\
\text { Iraci Franciosi } \\
\text { Iria da Silva Motta }\end{array}$ & $\begin{array}{l}4^{\mathrm{a}} \\
3^{\mathrm{a}} \\
2^{\mathrm{a}} \\
2^{\mathrm{a}} \\
1^{\mathrm{a}}\end{array}$ & $\begin{array}{l}32 \\
21 \\
21 \\
17 \\
28\end{array}$ & 119 \\
\hline 1972 & $\begin{array}{l}\text { Anastácia Leonora Brum } \\
\text { Iria da Silva Motta } \\
\text { Maria Izabel Marcinko } \\
\text { Albertina Alberti Piasecki } \\
\text { Jurema Marques Fritz }\end{array}$ & $\begin{array}{c}4^{\mathrm{a}} \\
3^{\mathrm{a}} \\
2^{\mathrm{a}} \\
1^{\mathrm{a}} \\
\text { Pré- } \\
\text { primário }\end{array}$ & $\begin{array}{l}28 \\
26 \\
32 \\
27 \\
16\end{array}$ & 129 \\
\hline $\begin{array}{c}1973 \\
\text { M e T }\end{array}$ & $\begin{array}{c}\text { Edith Rocha Mezzomo } \\
\text { Olga Pereira Muzyka } \\
\text { Maria Izabel Marcinko } \\
\text { Ione Valderez Cordeiro Henke }\end{array}$ & $\begin{array}{l}4^{\mathrm{a}} \\
4^{\mathrm{a}} \\
3^{\mathrm{a}} \\
3^{\mathrm{a}}\end{array}$ & $\begin{array}{l}18 \\
20 \\
23 \\
29\end{array}$ & 204 \\
\hline
\end{tabular}


FAZ CIÊNCIA, VOL. 20, N. 32, JUL/DEZ 2018 - P. 09-28

\begin{tabular}{|c|c|c|c|c|}
\hline & $\begin{array}{c}\text { Terezinha Odete Dallago Volkman } \\
\text { Ligia Forvelli de Andrade } \\
\text { Albertina Alberti Piasecki } \\
\text { Anastácia Leonora Brum } \\
\text { Ione Levandoski }\end{array}$ & $\begin{array}{l}2^{\mathrm{a}} \\
2^{\mathrm{a}} \\
1^{\mathrm{a}} \\
1^{\mathrm{a}} \\
1^{\mathrm{a}}\end{array}$ & $\begin{array}{l}27 \\
21 \\
22 \\
23 \\
21\end{array}$ & \\
\hline 1974 & $\begin{array}{l}\text { Terezinha Odete Dallago Volkman } \\
\text { Ione Valderez Cordeiro Henke } \\
\text { Evanildes dos Santos Leite Henke } \\
\text { Maria Izabel Marcinko } \\
\text { Anastácia Leonora Brum } \\
\text { Olga Pereira Muzyka } \\
\text { Albertina Alberti Piasecki } \\
\text { Ione Levandoski }\end{array}$ & $\begin{array}{l}4^{\mathrm{a}} \\
4^{\mathrm{a}} \\
3^{\mathrm{a}} \\
3^{\mathrm{a}} \\
2^{\mathrm{a}} \\
2^{\mathrm{a}} \\
1^{\mathrm{a}} \\
1^{\mathrm{a}}\end{array}$ & $\begin{array}{l}17 \\
15 \\
19 \\
29 \\
26 \\
24 \\
18 \\
19\end{array}$ & 167 \\
\hline $\begin{array}{c}1975 \\
\mathrm{Me} \mathrm{T}\end{array}$ & $\begin{array}{c}\text { Maria Izabel Marcinko } \\
\text { Anastácia Leonora Brum } \\
\text { Evanildes dos Santos Leite Henke } \\
\text { Olga Pereira Muzyka } \\
\text { Terezinha Odete Dallago Volkman } \\
\text { Amélia Josefi }\end{array}$ & $\begin{array}{l}4^{\mathrm{a}} \\
3^{\mathrm{a}} \\
2^{\mathrm{a}} \\
2^{\mathrm{a}} \\
1^{\mathrm{a}} \\
1^{\mathrm{a}}\end{array}$ & $\begin{array}{l}42 \\
25 \\
18 \\
18 \\
19 \\
17\end{array}$ & 139 \\
\hline 1976 & $\begin{array}{c}\text { Terezinha Odete Dallago Volkman } \\
\text { Anastácia Leonora Brum } \\
\text { Ione Valderez Cordeiro Henke } \\
? \\
?\end{array}$ & $\begin{array}{l}4^{\mathrm{a}} \\
4^{\mathrm{a}} \\
3^{\mathrm{a}} \\
2^{\mathrm{a}} \\
1^{\mathrm{a}}\end{array}$ & $\begin{array}{l}26 \\
22 \\
32 \\
42 \\
37\end{array}$ & 159 \\
\hline 1977 & $\begin{array}{c}\text { Anastácia Leonora Brum } \\
\text { Maria Izabel Marcinko } \\
\text { Ione Valderez C. Henke/Amélia Josefi } \\
\text { Albertina A. Piasecki/ Ione Levandoski }\end{array}$ & $\begin{array}{l}4^{\mathrm{a}} \\
3^{\mathrm{a}} \\
2^{\mathrm{a}} \\
1^{\mathrm{a}}\end{array}$ & $\begin{array}{l}34 \\
49 \\
43 \\
49\end{array}$ & 175 \\
\hline 1978 & $\begin{array}{c}\text { Maria Izabel Marcinko/ ? } \\
\text { Amélia Josefi/ ? } \\
\text { Francisca de Oliveira/? } \\
\text { Albertina A. Piasecki/ Ione Levandoski }\end{array}$ & $\begin{array}{l}4^{\mathrm{a}} \\
3^{\mathrm{a}} \\
2^{\mathrm{a}} \\
1^{\mathrm{a}}\end{array}$ & $\begin{array}{l}63 \\
62 \\
58 \\
66\end{array}$ & 249 \\
\hline 1979 & $\begin{array}{l}? \\
? \\
? \\
?\end{array}$ & $\begin{array}{l}4^{\mathrm{a}} \\
3^{\mathrm{a}} \\
2^{\mathrm{a}} \\
1^{\mathrm{a}}\end{array}$ & $\begin{array}{l}66 \\
58 \\
63 \\
63\end{array}$ & 250 \\
\hline 1980 & $\begin{array}{l}? \\
? \\
? \\
?\end{array}$ & $\begin{array}{l}4^{\mathrm{a}} \\
3^{\mathrm{a}} \\
2^{\mathrm{a}} \\
1^{\mathrm{a}}\end{array}$ & $\begin{array}{l}41 \\
61 \\
53 \\
60\end{array}$ & 215 \\
\hline
\end{tabular}

Observando o quadro, notamos o salto do número de alunos matriculados nos anos de 1973 e 1978. Em ambas as datas, o aumento está relacionado com a mudança de local da escola. Em 1973 quando deixou de dividir espaço com a Escola Normal Colegial e foi transferida para um local maior que continha mais salas disponíveis e a escola poderia inclusive, funcionar em 
dois turnos como de fato ocorreu. Já em 1978 a transferência foi para o prédio novo da escola inaugurado no início daquele ano.

Quanto aos turnos de funcionamento da escola, não podemos afirmar com exatidão, devido a falta de registros precisos, no entanto é possível fazermos um exercício de inferência para concluir que entre 1968 a 1972 ela funcionou apenas no período vespertino considerando que pela manhã funcionava a Escola Normal Colegial Estadual Dr. Leôncio Correia no mesmo local. Entre 1973 a 1977 quando ocupou sozinha as instalações cedidas pela Associação das Damas de Caridade, é possível que tenha ofertado turmas nos períodos matutino e vespertino ou apenas um variando conforme a demanda. Entre 1978 a 1980 acreditamos que ela funcionou apenas no período vespertino, em razão da existência dos cursos de Magistério, Básico em Agropecuária e Contabilidade que funcionavam no Colégio Estadual Honório Babinski.

Com relação ao corpo docente, cabe salientar que havia ainda as professoras que exerciam os cargos técnicos como diretora, secretária e coordenadora, além da professora das turmas de pré-primário que não aparecem nos registros, com exceção do ano de 1972. Além destas docentes citadas no quadro anterior, encontramos, em documentos diversos, o registro de outras professoras que deram aulas na Escola de Aplicação até o ano de 1980: Amélia Carvalho, Arlete Amaral, Adair Cordeiro Rabel, Beatriz Camargo, Conceição Oliveira, Elaine M. Camargo, Glayz Mary Chemin Glomb, Letícia Molinari, Luiza Molinari, Maria das Graças Taques, Nilza Rosa Rodrigues, Sebastiana Maria Vieira, Valquíria Brzezinski e Zulsi Maria Teixeira Rohr (LEMIECHEK, 2014).

Apesar de não constar nos registros de matrículas, ou em qualquer outro documento, de acordo com depoimentos das professoras Maria Izabel Marcinko e Anastácia Leonora Brum no ano de sua fundação a escola inovou ofertando vagas para uma turma de Jardim de Infância ou Pré-Primário. Até aquela data, não havia o atendimento aos alunos nessa faixa etária no Grupo Escolar Aluísio Maier, na Escola Adventista e nem no Colégio Vicentino Santa Ana, embora essas instituições já estivessem em atividade há décadas.

\section{Aspectos pedagógicos}

Em relação às práticas pedagógicas, a Escola de Aplicação seria uma escola-modelo, considerando sua essência legal que era servir de campo para as práticas das modernas teorias e procedimentos pedagógicos apreendidos pelos normalistas. Embora fosse o local onde, teoricamente, os normalistas exerceriam a prática não conseguimos localizar registros escritos da passagem de estagiários pela escola a não ser o relato oral da professora Sueli Berger Kailer que fez sua regência na instituição no ano de 1980 quando esta fazia parte do $1^{\circ}$ Grau do Colégio 
Estadual Professor Gildo Aluísio Schuck. Ainda, em conversa informal com a professora Ligia Regina Klein esta afirmou ter feito estágio na Escola de Aplicação no final da década de 1960. Desta forma, embora sem registros formais, sabemos que esses estágios ocorreram conforme a legislação previa.

No início, o quadro docente era formado basicamente por professoras recém-formadas na Escola Normal Colegial Estadual Dr. Leôncio Correia e pelos relatos, percebemos que as professoras realmente inovaram em algumas práticas. Segundo depoimento da professora Maria Izabel, em sua vida profissional ela sempre trabalhou com $3^{\mathrm{a}}$ e $4^{\mathrm{a}}$ séries e, no ano de 1975 , participou de uma experiência inovadora com os alunos de $4^{\mathrm{a}}$ série. Ela assim relatou:

[...] foi feita uma experiência de um ou dois anos que a gente fez aquilo. Uma trabalhava Português, outra trabalhava a parte de Estudos Sociais e a outra trabalhava Matemática. Nosso objetivo era preparar o aluno para o ginásio. [...] Mas depois, na outra escola mudou a direção. Quando a Tereza saiu foi a Olga Muzyka. No tempo da Olga a gente não fez mais assim. Daí cada uma era responsável pela sua turma (MARCINKO, 2014).

Segundo seu depoimento, essa foi uma forma encontrada pelos professores para reduzir os impactos sentidos pelos alunos quando ingressavam no ginásio onde teriam um professor para cada disciplina. Embora, para ela, a experiência tenha sido bem-sucedida não soube dizer porque não teve continuidade.

De acordo com Lemiechek (2014), os programas a serem trabalhados pelos docentes eram estipulados pelo Governo do Estado, numa espécie de "receituário" e eram repassados por meio da $46^{\text {a }}$ Inspetoria Regional de Ensino. Na escola, eram separados por bimestre e entregues aos professores pela direção ou coordenação. Com os conteúdos em mãos era feito o planejamento, no princípio aos sábados, quando as professoras se reuniam, discutiam, planejavam e trocavam atividades.

Separados por bimestre. Tudo direitinho, daí todos os professores já trabalhavam dentro dos mesmos conteúdos. A gente se organizava e fazia reuniões. Uma vez fazia no sábado. Muito tempo foi no sábado. Fazia os planos mais ou menos iguais e por série. Daí trocava as atividades e ia trabalhando (MARCINKO, 2014).

Com relação à formação continuada das docentes que atuavam na Escola de Aplicação, localizamos o registro de encontros do Curso de Aperfeiçoamento e Fundamentação Didáticopedagógica $-1^{\circ}$ grau Expansão III para o pessoal técnico e administrativo organizado pelo Centro de Seleção, Treinamento e Aperfeiçoamento de Pessoal do Paraná (CETEPAR) entre os meses de agosto a outubro de 1975 coordenado pela diretora, à época professora Terezinha Zempulski. Tratava-se da preparação para a implantação da Reforma de Ensino determinada pela 
Lei $\mathrm{n}^{\mathrm{o}} 5.692 / 71$. Os encontros no mês de agosto foram realizados na escola e a ata registrou a participação e discussão das questões e o bom entendimento por parte dos professores. As reuniões seguiam uma metodologia que incluía leitura e estudos individuais, trabalho em grupos menores e socialização para o grande grupo formado por aproximadamente 10 pessoas. Os temas trabalhados nessa etapa foram: Reforma do Ensino; deficiências do antigo sistema (excesso de memorização e pouca compreensão, programa extenso); conceitos como equilibração, assimilação, acomodação, afetividade, motivação e incentivação; estágios do desenvolvimento mental (estrutura, esquemas inatos do recém-nascido, estágio pré-conceitual, transdução, sincretismo, estágio das operações concretas); Lei $\mathrm{n}^{\circ}$ 5.692/71 e pareceres a ela relacionados; planejamento: conceito, etapas, elementos, princípios filosóficos da escola, projetos.

A ata registra que no dia 08 de setembro foi dado início a uma nova fase chamada de Curso de Treinamento que contou com a presença de professores das demais escolas e também de outros municípios no salão do Grêmio Estudantil José da Maia anexo à Escola Érico Veríssimo. Nesse evento foram socializadas as dúvidas dos professores que se resumiram às seguintes: diferenciação entre transdução e sincretismo; terminalidade do $1^{\circ}$ grau; como atender aluno infra e superdotados; prazos para implantação do plano da Reforma; diferença entre matéria, disciplina e área de estudo; atendimento ao desenvolvimento das potencialidades e diferenças individuais; objetivos da Reforma e o homem que se quer formar; proposições de Rogers; aprendizagem.

A continuação dessa etapa ocorreu nos dias 9, 10 e 11 de setembro, e também nos dias 4, 8, 29, 30 e 31 de outubro com um trabalho conjunto entre as professoras da Escola de Aplicação e do Colégio Vicentino Santa Ana. Nesse primeiro dia trabalhou-se com a seguinte provocação:

Uma patologia de certas escolas é a seguinte: 1. professores que se tornam profissionais do falar; 2. alunos profissionais do ouvir; 3. uns vendem saliva, outros preenchem fichário de memória. Nesse caso, professores e alunos apresentam-se como respectivamente sendo: os que sabem e os que não sabem (saber o que?); os que mandam e os que são mandados (mandar o que?); os que decidem e os que executam (executar o que?); os que educam e os que são educados (educados pra que?); os que disciplinam e os que são disciplinados (disciplinados pra que?). A questão é: na nossa escola existe esse tipo de relacionamento? Até que ponto? (LEMIECHEK, 2014, p. 224).

Outros temas trabalhados pelos professores durante o curso foram: o ato de educar; a indisciplina; técnicas e metodologias de ensino; criação e funcionamento de APPs; planejamento de aulas; confecção de material didático; Plano de Implantação da Reforma de ensino. Os professores reuniram-se também por série para fazer o Plano de Atividades por disciplina; 
trabalharam os conteúdos, objetivos, seleção e organização, avaliação do rendimento escolar (instrumentos, critérios, formas de avaliação); Conselho de Classe.

Desta forma, durante a capacitação, as discussões abrangeram a implantação da Lei $n^{\circ}$ 5.692 que reorganizou o ensino primário, atrelando-o ao ginasial compondo o Ensino de $1^{\circ} \mathrm{Grau}$ e foi um período de intenso trabalho, discussão e reflexão para os professores de todo o município.

Alguns registros indicam que os problemas enfrentados na Escola de Aplicação eram os mesmos que ocorriam, e ainda ocorrem, em qualquer outro estabelecimento de ensino fazendo parte do cotidiano escolar. Segundo registros localizados em ata de reunião pedagógica era atribuição das professoras: cobrar dos alunos o uso do uniforme, a pontualidade e assiduidade e o cuidado com o próprio material; corrigir as tarefas solicitadas aos alunos; evitar aulas monótonas e rotineiras; ser simpática e agradável mostrando-se otimista e alegre com os alunos incentivando e nunca humilhando; ter um olhar especial sobre os alunos que apresentavam dificuldades; evitar faltas e atrasos; não interferir no trabalho alheio; usar o uniforme; cultivar a harmonia e respeito no ambiente de trabalho. Percebe-se que havia um constante apelo para que as professoras ficassem atentas à determinadas ações do dia a dia que eram importantes e certamente contribuíam para o bom andamento das atividades pedagógicas e consequentemente para o sucesso do aluno. Em ata de reunião ocorrida no dia 19 de abril de 1977 há o seguinte registro:

A orientadora da escola Valquiria Brzezinski, falou sobre: preparação de leitura, leitura variada, jogral, júri, histórias. Intercalar atividades com recreação, preparar o diário. Uso correto dos termos matemáticos. Procurar escrever corretamente no quadro. Aplicação de teste com severidade para que o aluno seja medido da melhor forma possível. Não deixar de ministrar aulas de Educação Física, observar leitura silenciosa e todos os bons hábitos, preparar bem o assunto a dar. Fixar bem qualquer assunto ministrado. Novamente a diretora dirigiu a palavra, dando conselhos diversos para que a escola tenha bom nome perante a comunidade (LEMIECHEK, 2014, p. 225 e 226)

Segundo a professora Maria Izabel, nessa época, início dos anos 1970, não havia muitos recursos audiovisuais que pudessem ser utilizados. Tudo era de difícil acesso. Mas, já havia o mimeógrafo e seu uso se apresentava como uma grande novidade que facilitava a vida do docente na hora da confecção das provas e trabalhos para colorir.

No que se refere aos livros didáticos utilizados, a professora Maria Izabel afirma que:

[...] os pais compravam. Naquele tempo a gente já recebia das editoras os exemplares. Antes do final do ano já começavam a mandar e daí a gente escolhia. No meu tempo, teve uns anos que a Tereza fazia o pedido. Fazia o pedido e cobrava da piazada. Nas livrarias não sei se a gente usou. Nos últimos anos, já vinha pelo Estado, mas geralmente era comprado (MARCINKO, 2014). 
Embora a professora não se recorde, o registro em ata de reunião ocorrida no dia $1^{\circ}$ de março de 1977 indica que não haveria mais a interferência da escola na venda dos livros naquele ano e os pais deveriam comprar diretamente nas livrarias da cidade. A professora Maria Izabel não soube informar os títulos dos livros didáticos utilizados por ela nas atividades com os alunos de $3^{\mathrm{a}}$ e $4^{\mathrm{a}}$ séries. No entanto, como uma das protagonistas da história da Escola de Aplicação, em nossa memória está viva a imagem da cartilha $O$ sonho de Talita com a qual fomos alfabetizados pela professora Amélia Josefi no ano de 1975.

Página da cartilha $O$ sonho de Talita

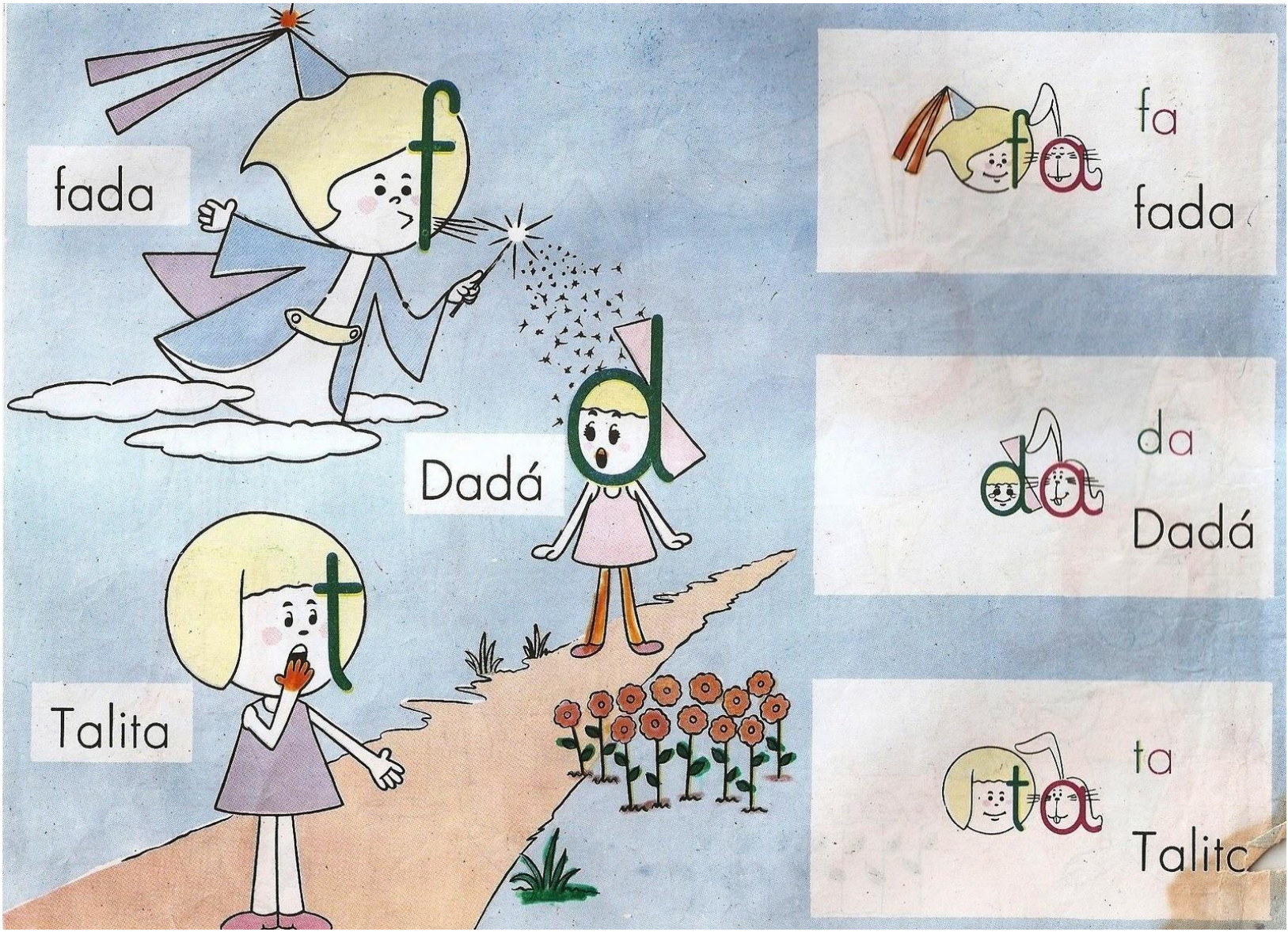

Fonte: http://gisasanti.blogspot.com.br/2011/03/sonho-de-talita.html

Essa cartilha foi escrita por Manoelita Marcello Pimenta Bueno e Maria do Carmo Freitas Guimarães com ilustrações de Luiz César e publicada pela Editora E. C. D - Editora Didática e Científica LTDA do Rio de Janeiro e (Instituto de Educação do Rio de Janeiro - BLOG, 2014). A cartilha era acompanhada do Caderno de Atividades para fazer os exercícios de fixação. Sua proposta de alfabetização era partir de palavras-chave consideradas significativas para os alunos e retiradas do contexto onde havia história, gravura, conversa ou leitura feita por um adulto (professor). As novas letras eram associadas à personagens que se envolviam em histórias com a 
fada e a menina Talita, personagens centrais da cartilha. Havia a preocupação com a progressão das dificuldades, começando pelas vogais de forma isolada, na sequência eram apresentadas as sílabas mais simples e em seguida as complexas num método classificado como silábico e sintético (quando se avança das partes para o todo). O livro de atividades, além dos exercícios propostos, trazia ainda a possibilidade de pintar as figuras considerando que era em preto e branco.

\section{Outros aspectos relevantes}

Com relação à merenda escolar, a professora Maria Izabel Marcinko afirmou que ela era oferecida e que os alunos a recebiam por meio da Fundação Estadual de Ensino do Paraná (FUNDEPAR), órgão criado pelo Governo do Estado no ano de 1962, que além da construção de prédios escolares, realização de cursos de capacitação, atendimento à saúde do educando, entre outras ações, gerenciava o programa de Merenda Escolar nas instituições de ensino públicas.

Quanto ao uniforme, era adotado pela escola e ficava sob a responsabilidade dos pais sendo calça ou saia azul-marinho e camisa branca. Aos alunos do Jardim de Infância não era exigido o uso do uniforme, no entanto solicitava-se o uso de um jaleco em tecido xadrez vermelho. Este tinha como função, proteger a roupa das crianças nas atividades ao ar livre e também no trabalho com tinta ou outros materiais.

Segundo o que determinava a lei, havia a época dos exames finais e os alunos que deles participavam eram avaliados por uma Banca Examinadora composta pela professora regente, uma professora aplicadora e uma fiscal. Além dos membros da banca, assinava a ata também a diretora do estabelecimento.

Embora o primário fosse o nível elementar da educação formal, hoje chamado de anos iniciais do Ensino Fundamental com cinco séries, ele era uma etapa importante, considerando que nem todos os alunos prosseguiam os seus estudos por inúmeros motivos. Desta forma, a conclusão da $4^{\text {a }}$ série era considerada um fechamento de ciclo e, ao mesmo tempo, uma importante conquista na vida dos alunos. Assim, era comum a realização de cerimônias de formatura com a entrega dos certificados de conclusão do ensino primário para os alunos da Escola de Aplicação. 
Alunos da $4^{\mathrm{a}}$ série da Escola de Aplicação durante cerimônia de entrega de certificados de conclusão do ensino primário. Sem data.

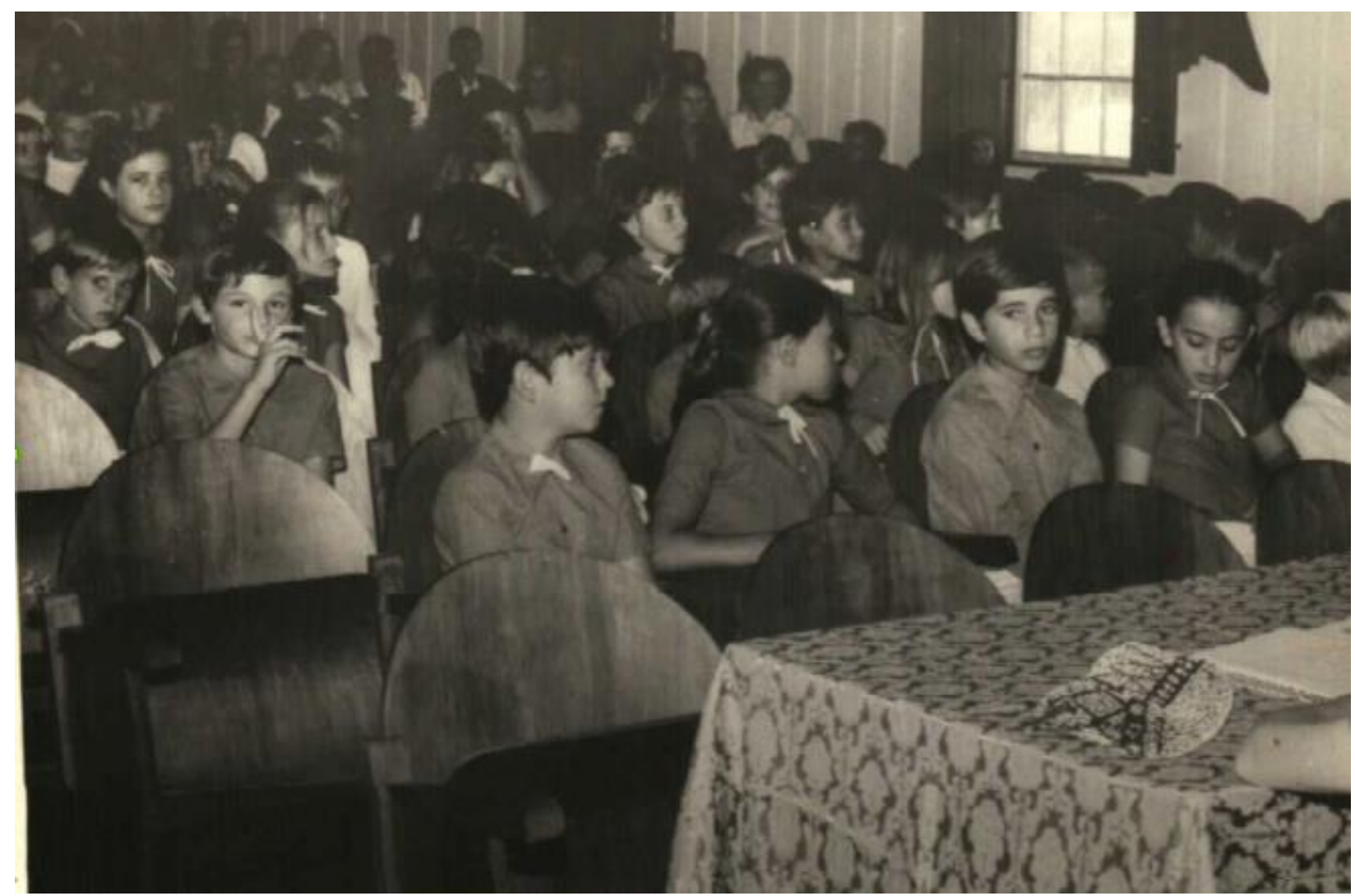

Fonte: Acervo pessoal de Anastácia Leonora Brum

\section{Considerações finais}

Infelizmente, a exemplo do aconteceu com outras escolas investigadas durante a realização da pesquisa que deu origem a esse artigo, a reconstrução de aspectos históricos da Escola de Aplicação ficou prejudicada pela dificuldade no trabalho com as fontes tendo em vista a existência de poucos e incompletos documentos. Estes, foram se perdendo com a passagem do tempo e até mesmo pelas mudanças de sede da escola, com a documentação ficando aos cuidados de um grande número de pessoas. $\mathrm{O}$ fato de ter estado sob a dependência administrativa do Estado, e depois do município, também pode ter contribuído para que se perdessem fontes consideráveis que são produzidas no interior de uma instituição de ensino e que ajudariam a reconstruir sua história deixando à tona a riqueza de fatos ocorridos nessas duas décadas e meia de atividades. Desta forma, os relatos orais foram imprescindíveis para a recuperação de dados sobre a instituição.

Acerca do motivo legal para sua criação, o campo de práticas da Escola Normal, consideramos que, embora não haja relatos escritos, houve a realização de estágios e regência de classe na escola. No entanto, não podemos afirmar que os normalistas, orientados por seus 
professores, desenvolveram projetos na instituição. No que diz respeito à inserção das egressas da Escola Normal Secundária no mercado de trabalho, é fato que houve a contratação de normalistas, no entanto, também ocorreu ingerência política na admissão de docentes fato este que colocava, na sala de aula, profissionais inabilitados contrariando o que determinava a lei. Com relação ao suprimento de vagas para o ensino primário no quadro urbano, houve uma grande procura pelo estabelecimento fazendo com que o problema de superlotação do Grupo Escolar Aluísio Maier, fosse atenuado.

Desta forma, podemos concluir que, embora os objetivos elencados para a criação da Escola de Aplicação tivessem sido apenas parcialmente alcançados ao longo dos 25 anos que ela esteve em atividade, a instituição foi de extrema relevância para a área educacional do município de Laranjeiras do Sul.

\section{Referências}

BRASIL. Decreto-Lei no 8.530, de 2 de janeiro de 1946. Lei Orgânica do Ensino Normal. Disponível em: <http://www2.camara.leg.br/legin/fed/declei/1940-1949/decreto-lei-8530-2janeiro-1946-458443-publicacaooriginal-1-pe.html>. Acesso em: 28 de set. De 2013.

Lei $\mathbf{n}^{\circ}$ 5.692, de 11 de agosto de 1971. Fixa as Diretrizes e Bases da Educação Nacional para o ensino de $1^{\circ}$ e $2^{\circ}$ graus.

Território Federal do Iguaçu. Decreto no 2, de 21 de abril de 1946. Cria o Curso Normal Regional. In: Relatório de atividades do Governador Frederico Trotta encaminhado para o presidente Eurico Gaspar Dutra em 1946. Rio de Janeiro: Imprensa Nacional, 1947.

HERVATINI, Luciana. A escola normal regional e suas práticas pedagógicas: dois retratos de um mesmo cenário no interior do Paraná. Maringá: Universidade Estadual de Maringá. Dissertação de mestrado, 2011.

LEMIECHEK, Lucimara. Aspectos históricos da formação de professores normalistas no município de Laranjeiras do Sul - PR (1946 - 1980). Francisco Beltrão: Universidade Estadual do Oeste do Paraná - UNIOESTE. Dissertação de mestrado, 2014.

MIGUEL, Maria Elisabeth Blanck. A formação do professor e a organização social do trabalho. Curitiba: Editora da UFPR, 1997.

TANURI, Leonor Maria. História da formação de professores. Revista Brasileira de Educação, n 14, mai/jun/jul/ago.2000.

REVISTA TRIBUNA LARANJEIRENSE. Edição comemorativa pelo $\mathbf{2 5}^{\circ}$ aniversário do município do município, ano III, 29/11/1971, composto e impresso na editora Lítero-técnica, Curitiba - PR.

ESCOLA DE APLICAÇÃO. Histórico sem data. Arquivo da Escola Normal Colegial Estadual Dr. Leôncio Correia, localizado no Colégio Estadual Professor Gildo Aluisio Schuck, 2013.

Ata do Curso de Aperfeiçoamento e Fundamentação Didático-pedagógica - $\mathbf{1}^{\mathbf{0}}$ grau Expansão III. 1975. Localizado no arquivo inativo da Escola Municipal Padre Gerson Galvino, 2014.

Ata de reunião pedagógica realizada em 1975. Localizada no arquivo inativo do Colégio Estadual Professor Gildo Aluísio Schuck. 2014. 
Ata de reunião pedagógica realizada em 1977. Localizada no arquivo inativo do Colégio Estadual Professor Gildo Aluísio Schuck. 2014.

Ata de registros dos exames finais. 1968 a 1976. Localizado no arquivo inativo da Escola Municipal Padre Gerson Galvino, 2014.

Histórico. Sem data. Localizado no arquivo inativo Colégio Estadual Prof. Gildo Aluísio Schuck, 2013.

Livro de registro de matrículas. Sem data. Localizado no Arquivo Inativo da Escola Municipal Padre Gerson Galvino, 2014.

. Livro de registro de Exames Finais. 1968 a 1976. Localizado no Arquivo Inativo da Escola Municipal Padre Gerson Galvino, 2014.

Livro de registro de Ponto dos docentes. Sem data. Localizado no Arquivo Inativo da Escola Municipal Padre Gerson Galvino, 2014.

PARANÁ. Decreto n ${ }^{\circ} 11.292$ de 11 de julho de 1957. Diário Oficial do Estado em 13 de julho de 1957. Cria a Escola Normal Secundária em Laranjeiras do Sul. In: Histórico da Escola Normal Colegial Estadual Dr. Leôncio Correia, sem data. Localizado no Colégio Estadual Professor Gildo Aluisio Schuck, 2013.

Decreto $\mathbf{n}^{\circ} 9.090$ de 24 de fevereiro de 1968. Cria a Escola de Aplicação anexa à Escola Normal Colegial Estadual Dr. Leôncio Correia. Localizado no Colégio Estadual Professor Gildo Aluisio Schuck, 2013.

Decreto $\mathrm{n}^{\circ} \mathbf{2 . 4 8 3}$ de 12 de junho de 1980. Autoriza o funcionamento do Complexo Escolar Dom Manoel Konner. In: Histórico do Colégio Estadual Professor Gildo Aluísio Schuck, localizado no Colégio Estadual Professor Gildo Aluísio Schuck, 2013.

Lei Estadual no 4.978 de 5 de dezembro de 1964. Estabelece o Sistema Estadual de Ensino. Conselho Estadual de Educação, 1965, nº 1, Governo do Estado do Paraná.

Resolução Secretarial no 2.121 de 22 de abril de 1993. Modifica a nomenclatura do $1^{\circ}$ Grau do Colégio Estadual Professor Gildo Aluisio Schuck para Escola Municipal Padre Gerson Galvino. In: Histórico da Escola Normal Colegial Estadual Dr. Leôncio Correia, localizado no Colégio Estadual Professor Gildo Aluisio Schuck, 2013.

http://gisasanti.blogspot.com.br/2011/03/sonho-de-talita.html. Acesso em 04 de maio de 2014.

http://institutodeeducacao.blogspot.com.br/2006/04/cartilha-da-talita.html. Acesso em 02 de maio de 2014.

\section{ENTREVISTAS}

BRUM, Anastácia Leonora. Entrevista. [fev. 2014]. Laranjeiras do Sul, Paraná. 2014. (57 min 54s). Entrevista concedida à Lucimara Lemiechek.

KAILER, Sueli Berger. Entrevista. [jun. 2014]. Laranjeiras do Sul, Paraná. 2014. (1h 14min 12 s). Entrevista concedida à Lucimara Lemiechek.

MARCINKO, Maria Izabel. Entrevista. [abr. 2014]. Laranjeiras do Sul, Paraná. 2014. (1h $2 \mathrm{~min}$ ). Entrevista concedida à Lucimara Lemiechek. 